\title{
Protective effect of hypoxia on bisphosphonate-related bone cell damage
}

\author{
MYUNG-HEE MOON ${ }^{1 *}$, JAE-WON SEOL ${ }^{2 *}$, JAE-SUK SEO ${ }^{1}$, JAE-KYO JEONG $^{1}$, YOU-JIN LEE ${ }^{1}$, \\ IN-SHIK KIM ${ }^{1}$, CHRIS JACKSON ${ }^{2}$, PHILIP SAMBROOK ${ }^{2}$ and SANG-YOUEL PARK ${ }^{1}$ \\ ${ }^{1}$ Center for Healthcare Technology Development, Bio-Safety Research Institute, College of Veterinary Medicine, \\ Chonbuk National University, Jeonju, Jeonbuk 561-756, Korea; ${ }^{2}$ Institute of Bone and Joint Research, \\ University of Sydney, Kolling Institute, Royal North Shore Hospital, St. Leonards, NSW 2065, Australia
}

Received May 3,2010; Accepted July 21, 2010

DOI: $10.3892 / \mathrm{mmr} .2010 .344$

\begin{abstract}
Bisphosphonates (BPs) are widely used for the prevention and treatment of osteoporosis. However, there have been numerous reports of side effects of BPs, including osteonecrosis of the jaw. In the present study, we investigated whether hypoxia inhibits BP-induced apoptosis, and examined the mechanisms of this inhibition. The cell viability of the MG 63 human osteoblast-like cell line treated with the nitrogencontaining (N)-BPs alendronate, risedronate and zoledronate was investigated, and hypoxia was assessed by crystal violet staining and the MTT assay, and by observing cell morphology. The effect of N-BPs and hypoxia on apoptotic cell signaling was evaluated using Western blotting, immunocytochemistry and the TUNEL assay. The results of crystal violet staining and the MTT and TUNEL assays showed that the N-BPs inhibited proliferation and induced apoptosis in MG 63 cells. Hypoxia significantly prevented N-BP-induced MG 63 cell apoptosis, and also attenuated BP-induced c-Jun N-terminal kinase (JNK) phosphorylation and BCL-xL reduction. Hypoxia prevented BP-induced cell damage by blocking JNK phosphorylation and by regulating the BCL-xL protein. Thus, hypoxia or hypoxia-related genes, including hypoxia-inducible factor $1 \alpha$, may be a potential therapy for BP-related side effects such as osteonecrosis of the jaw.
\end{abstract}

\section{Introduction}

Hypoxia has been clearly identified as a physiological abnormality associated with solid tumors and is markedly involved

Correspondence to: Dr Sang-Youel Park, Center for Healthcare Technology Development, Bio-Safety Research Institute, College of Veterinary Medicine, Chonbuk National University, Jeonju, Jeonbuk 561-756, Korea

E-mail: sypark@chonbuk.ac.kr

*Contributed equally

Key words: hypoxia, bisphosphonate, apoptosis, osteoporosis in the outcome of cancer treatment (1). Although hypoxia is toxic to both cancer and normal cells, cancer cells undergo genetic and adaptive changes that allow them to survive and even proliferate in a hypoxic environment (2). Exposure to long-term hypoxia results in resistance to apoptosis, as well as to radiotherapy and chemotherapy, and enhances survival signals (3-7). The main transcription factor involved in the adaptation to hypoxia is hypoxia-inducible factor 1 (HIF-1). HIF-1 modulates the activity of other transcription factors, including nuclear factor $\kappa \mathrm{B}(\mathrm{NF}-\kappa \mathrm{B}), \mathrm{p} 53$, c-myc and c-jun (8). In addition, $\mathrm{NF}-\kappa \mathrm{B}$ regulates the expression of anti-apoptotic effectors, such as Bcl-2, Bcl-xL, c-IAP2 or A1/Bfl1 (8).

Bisphosphonates (BPs) suppress osteoclastic bone resorption and are currently the most important class of antiresorptive drugs used for the treatment of metabolic bone diseases, and are also frequently used in oncology to treat bone complications (9-11). In osteoporosis, BPs are regarded as first-line therapy. Their antiresorptive action inhibits the function and survival of mature osteoclasts (12). Nitrogencontaining bisphosphonates (N-BPs) act on bone metabolism by binding and blocking the enzyme farnesyl diphosphate synthase (FPPS) in the 3-hydroxy-3-methylglutaryl coenzyme A (HMG-CoA) reductase pathway. Disruption of the HMG-CoA reductase pathway at the FPPS prevents the formation of two metabolites (farnesol and geranylgeraniol) essential for connecting various small proteins to the cell membrane. The addition of either of these two metabolites to proteins is known as prenylation, and is important for proper subcellular protein trafficking $(13,14)$. Inhibition of protein prenylation may affect many proteins found in an osteoclast, influencing osteoclastogenesis, cell survival and cytoskeletal dynamics (15-18). BPs also cause apoptosis and activate the MAPK and c-Jun N-terminal kinase (JNK) signaling pathways in osteoclasts and J774 macrophages in vitro (19). Various studies have shown that JNK induces cell apoptosis by phosphorylation and activation of the transcription factor p53 $(20,21)$ or by phosphorylation (and inactivation) of the anti-apoptotic proteins of the Bcl-2 family (22-24).

Through these antiresorptive mechanisms, BPs are widely used for the prevention and treatment of osteoporosis. However, recently there have been many reports of side effects associated with BP use. Among the potential adverse clinical 
events associated with the use of BPs, none has received greater attention than osteonecrosis of the jaw (ONJ) (25). The risk of ONJ associated with oral BP therapy for osteoporosis or Paget's disease was estimated to be between $1 / 10,000$ and $1 / 100,000$ patient-treatment years, although the true incidence may be higher $(26,27)$. The exact mechanisms of ONJ are not known, but one suggested mechanism is that BP causes an excessive reduction of bone turnover, leading to the accumulation of microfractures that make the bone susceptible to necrosis when there is increased demand for osseous repair owing to trauma or infection $(28,29)$.

Therefore, in this study we examined whether hypoxia regulates $\mathrm{BP}$-induced cell damage to determine the possibility of hypoxia as a therapeutic tool for ONJ. We showed for the first time that hypoxia inhibits BP-induced cell damage. In addition, the inhibitory mechanisms of hypoxia against the BP-induced cell damage linked to the JNK pathway were investigated.

\section{Materials and methods}

Materials. Human MG 63 osteoblast-like osteosarcoma cells were grown in DMEM with $10 \%$ fetal bovine serum (FBS) to $70 \%$ confluence. Cells were treated for 24 or $48 \mathrm{~h}$ with BPs at concentrations ranging from $10^{-3}$ to $10^{-5} \mathrm{M}$. Human osteoblastoma MG 63 cells were maintained in DMEM containing $10 \%$ FCS and supplemented with $100 \mathrm{U} / \mathrm{ml}$ of gentamicin. Prior to treatment, cells were pre-incubated for $2 \mathrm{~h}$ in DMEM with $1 \%$ FBS (basal medium). Cells were treated with alendronate (ALN) sodium trihydrate (Sigma), risedronate sodium (Actonel ${ }^{\circledR}$; Procter \& Gamble Pharmaceuticals) and zoledronic acid (Zometa ${ }^{\circledR}$; Norvartis).

Hypoxic treatment. A hypoxic chamber was used to create a low-oxygen environment, with a gas mixture of $1 \% \mathrm{O}_{2}$, $5 \% \mathrm{CO}_{2}$ and $94 \% \mathrm{~N}_{2}$ added to the sealed chamber and the ambient air evacuated by an outlet tube. The $\mathrm{O}_{2}$ flow was allowed to stream through the chamber for 2-3 min to maintain the desired $\mathrm{O}_{2}$ concentration inside the chamber. Culture plates were incubated in sealed chambers containing $1 \% \mathrm{O}_{2}$ at $37^{\circ} \mathrm{C}$.

\section{Determination of cell viability}

Direct microscopic observation. The hallmarks of cell degeneration were assessed by morphological criteria. After the proper treatment, the cells were photographed with a light microscope (Eclipse TS100; Nikon Corporation, Japan).

Crystal violet staining. The cells were plated in 12- or 24-well plates and placed under hypoxic conditions for $12 \mathrm{~h}$, then incubated with ALN from 25 to $200 \mu \mathrm{M}$ for $72 \mathrm{~h}$. Cell morphology was photographed under a light microscope, and cell viability was determined by the crystal violet staining method as previously described (30). Briefly, the cells were stained for $10 \mathrm{~min}$ at room temperature with staining solution $(0.5 \%$ crystal violet in $30 \%$ ethanol and $3 \%$ formaldehyde), washed four times with water and then dried. The cells were then lysed with $1 \%$ SDS solution, and the absorbance was measured at $550 \mathrm{~nm}$. Cell viability was calculated based on the relative dye intensity compared to the controls.
Trypan blue exclusion test. Cells were plated in 6- or 12-well plates and placed under hypoxic conditions for $12 \mathrm{~h}$. They were then incubated with ALN or risedronate for additional experimental hours. Cell viability was determined by the trypan blue exclusion method as previously described (31). Briefly, a $100-\mu 1$ portion of resuspended cell pellet was placed in $100 \mu \mathrm{l}$ trypan blue $(0.5 \%$ dilution in $0.85 \% \mathrm{NaCl})$. Subsequently, $10 \mu \mathrm{l}$ of the cell suspension was loaded into a hemacytometer and the proportion of non-viable to viable cells was determined.

MTT assay. The colorimetric 3-[4,5-dimethylthiazol-2-yl]2,5-diphenyl tetrazolium bromide (MTT) assay was performed to quantify the effect of different test agents on cell viability and to standardize the loading of gels. Briefly, $2 \times 10^{4}$ cells/ well were seeded in a 96-well microplate at a final volume of $200 \mu \mathrm{l}$, incubated overnight and treated with test agents for $24 \mathrm{~h}$. Three hours prior to the completion of the treatment, $10 \mu \mathrm{l}$ of $5 \mathrm{mg} / \mathrm{ml}$ MTT (Sigma) was added to the cells, then the cells were further incubated for $3 \mathrm{~h}$. The MTT solution was then removed and replaced by $100 \mu \mathrm{l}$ dimethylsulfoxide, and the plates were agitated for $3 \mathrm{~min}$. The optical density was determined at a wavelength of $570 \mathrm{~nm}$.

Lactate dehydrogenase cytotoxicity test. Lactate dehydrogenase (LDH) activity in the previously frozen supernatants was measured using a cytotoxicity detection kit (Takara Bio Inc., Shiga, Japan) according to the manufacturer's instructions.

TUNEL assay. Terminal uridine deoxynucleotidyl transferase dUTP nick end labelling (TUNEL) analysis was performed to measure the degree of cellular apoptosis using an in situ ApoBrdU DNA fragmentation assay kit (BioVision, Mountain View, CA, USA) following the manufacturer's instructions. Cells were fixed by suspension in $70 \%$ (v/v) ethanol and stored at $-20^{\circ} \mathrm{C}$ overnight. The sample was then incubated with DNA-labeling solution (10 $\mu 1$ reaction buffer, $0.75 \mu 1 \mathrm{TdT}$ enzyme, $8 \mu \mathrm{l}$ BrdUTP, $31.25 \mu \mathrm{l}$ of $\mathrm{dH}_{2} \mathrm{O}$ ) for $1 \mathrm{~h}$ at $25^{\circ} \mathrm{C}$. Each sample was then exposed to an antibody solution consisting of $5 \mu$ Alexa Fluor ${ }^{\circledR}$ 488-labeled anti-BrdU antibody with $95 \mu 1$ rinse solution and allowed to react for $20 \mathrm{~min}$. Images were captured at x20 objective using a fluorescence microscope (Nikon Eclipse 80i; Nikon Corporation).

Western blotting. MG 63 cells were lysed in a lysis buffer [25 mM HEPES (pH 7.4), 100 mM NaCl, 1 mM EDTA, 5 mM $\mathrm{MgCl}_{2}, 0.1 \mathrm{mM}$ DTT and protease inhibitor mixture]. Proteins were electrophoretically resolved on an $8-15 \%$ sodium dodecyl sulfate (SDS) gel, and immunoblotting was performed as previously described (32). Equal amounts of lysate protein were resolved on an 8-15\% SDS-polyacrylamide gel and electrophoretically transferred to a nitrocellulose membrane. Immunoreactivity was detected through sequential incubation with horseradish peroxidase-conjugated secondary antibodies and ECL reagents. The antibodies used for immunoblotting were Rap 1A, p-JNK, cleaved caspase-3, Bcl-xL and $\beta$-actin (Santa Cruz Biotechnology, Santa Cruz, CA, USA).

Immunofluorescent staining. MG 63 cells cultured on glass slides were fixed with cold acetone, blocked by $5 \%$ FBS in TBST and incubated with mouse Bcl-2 antibody (Santa Cruz 
A

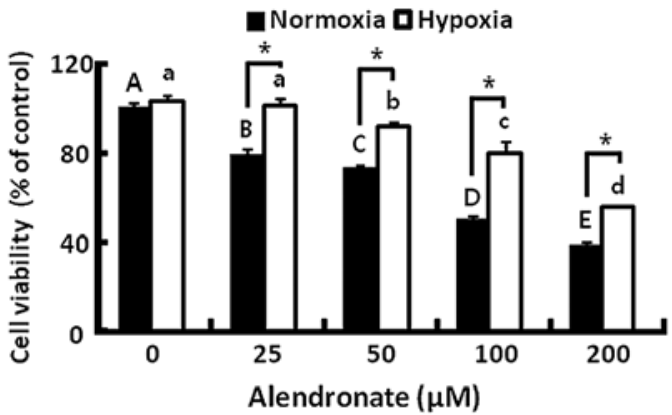

B

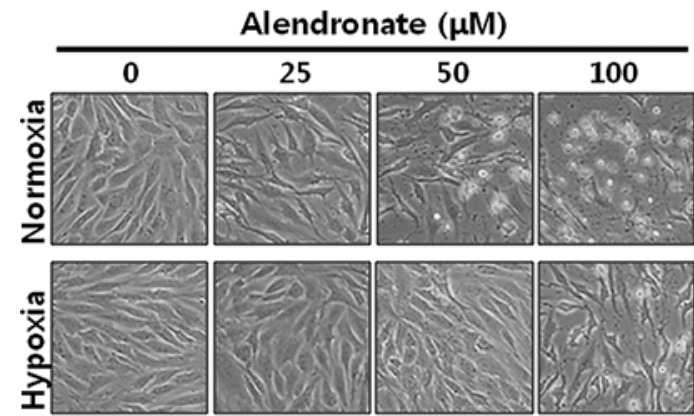

C

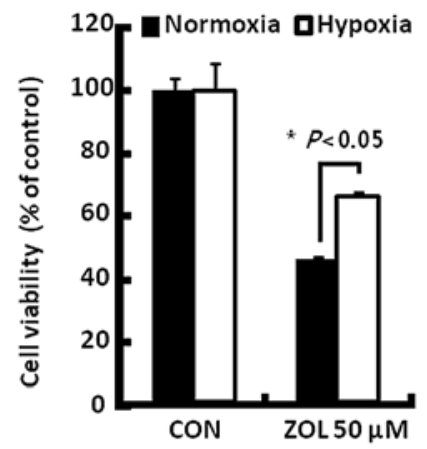

D

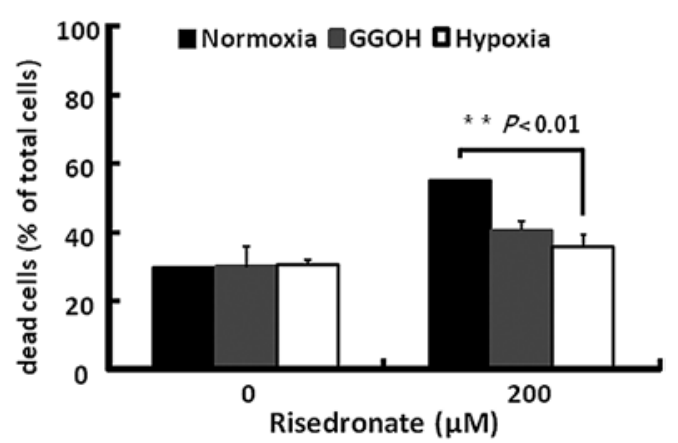

Figure 1. Hypoxia inhibits MG 63 cell death induced by N-BPs. (A) Alendronate (ALN) inhibited the viability of MG 63 cells. This was reversed by exposure to hypoxic conditions. MG 63 cells were exposed to hypoxic conditions for $12 \mathrm{~h}$ and treated with ALN dose-dependently for $72 \mathrm{~h}$. Cell viability was determined using the crystal violet staining method. Viability of control cells was set at 100\%, and viability was presented relative to the control. (B) Cell morphology was photographed (x200) under the indicated conditions. (C) Zoledronate (ZOL) induced apoptotic cell death in a dose-dependent manner. MG 63 cells plated in 96 wells were exposed to hypoxic conditions for $12 \mathrm{~h}$ and treated with ALN at the indicated doses for $72 \mathrm{~h}$. Cell viability was determined by the MTT assay. Viability of control cells was set at $100 \%$, and viability was presented relative to the control. (D) Risedronate induced apoptotic cell death at a concentration of $200 \mu \mathrm{M}$ and was reversed by $10 \mu \mathrm{M}$ of geranylgeranyl diphosphate (GGOH) under hypoxic conditions. Cells were collected and quantified, and cell death was assessed by trypan blue exclusion and expressed as the number of dead cells over the total number of cells. Data were analyzed using analysis of variance (ANOVA) and Duncan's multiple range test. Group means with different alphabets in $\mathrm{A}$ differed significantly $(\mathrm{P}<0.05)$. ${ }^{*}<0.05$; ${ }^{* *} \mathrm{P}<0.01$, significantly different from the control.

Biotechnology) and rabbit active caspase-3 antibody (R\&D Systems) overnight at $4^{\circ} \mathrm{C}$. After washing with TBST, the cells were incubated with goat anti-mouse $\operatorname{IgG}$ conjugated with Alexa Fluor 488 (green) and goat anti-rabbit IgG conjugated with Alexa Fluor ${ }^{\circledR} 546$ (red). Cells were washed with TBST, mounted with fluorescence mounting medium (Dako) and observed under a fluorescence microscope (Nikon Eclipse 80i). Images were acquired and processed using a Nikon digital camera and software (Diagnostic Instruments, Australia) as well as Image $\mathbf{J}$ software.

Statistical evaluation. Data are expressed as the means \pm standard deviation (SD) and were compared using the Student's t-test and the ANOVA Duncan test with the SAS Statistical package. The results were considered significant at values of $\mathrm{P}<0.05$ and $\mathrm{P}<0.01$.

\section{Results}

Hypoxia inhibits BP-induced MG 63 cell death. The effects of hypoxia on the viability of MG 63 cells treated with BPs were investigated. ALN inhibited MG 63 cell growth in a concentration-dependent manner at concentrations $>50 \mu \mathrm{M}$ (Fig. 1A). Exposure to hypoxic conditions for $84 \mathrm{~h}$ reversed ALN-induced MG 63 cell death. MG 63 cells were exposed to hypoxic conditions for $12 \mathrm{~h}$ and then treated with ALN dose-dependently for $72 \mathrm{~h}$. Physical indicators of cell death in MG 63 cells exposed to 50, 100 or $200 \mu \mathrm{M}$ of ALN were determined microscopically. Initial cell damage at $200 \mu \mathrm{M}$ was visualized as early as $24 \mathrm{~h}$ of incubation, whereas damage to the 50 and $100 \mu \mathrm{M}$-treated cells was observed at 48 and $36 \mathrm{~h}$, respectively (data not shown). After 24 h, MG 63 cells appeared to fragment and detach from the culture dish in a dose-dependent manner in response to ALN (Fig. 1B). Hypoxia reversed ALN-induced cell death.

The inhibitory effect of zoledronate $(50 \mu \mathrm{M})$ and risedronate $(200 \mu \mathrm{M})$ on MG 63 cell viability was reversed by hypoxia (Fig. 1C). BPs induce apoptosis by inhibiting the prenylation of small $\mathrm{G}$ protein families (33). This is prevented by the addition of exogenous isoprenoid lipids, such as farnesol and geranylgeraniol (GGOH), which replenish the cytosolic isoprenoid substrate (17,34-36). Therefore, we examined the effects of exogenous GGOH on cell viability. GGOH at $10 \mu \mathrm{M}$ recovered cell death induced by risedronate. Hypoxia was also effective at inhibiting cell death (Fig. 1D).

DNA fragmentation and activation of caspase-3 in $M G 63$ cells are stimulated by BPs and blocked by hypoxia. To confirm whether exposure to hypoxic conditions mitigated the apoptosis caused by BPs, DNA fragmentation and the activation of caspase-3 were examined. DNA fragmenta- 
A
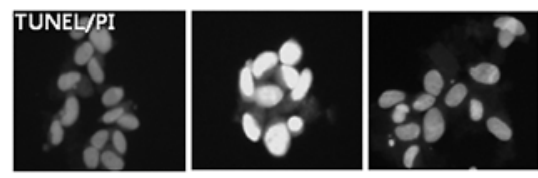

Hypoxia -

ALN

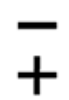

B

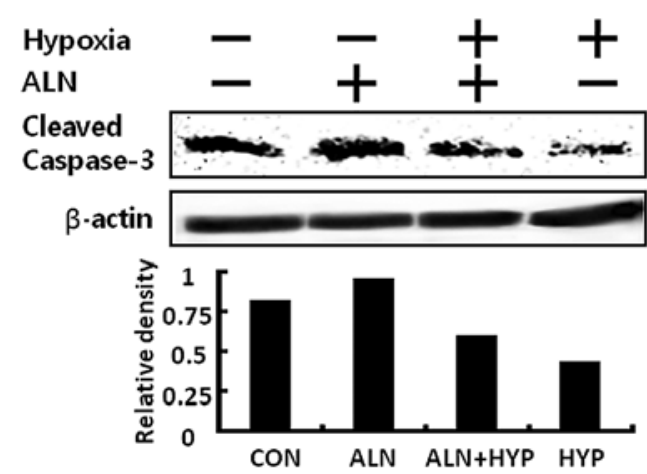

C

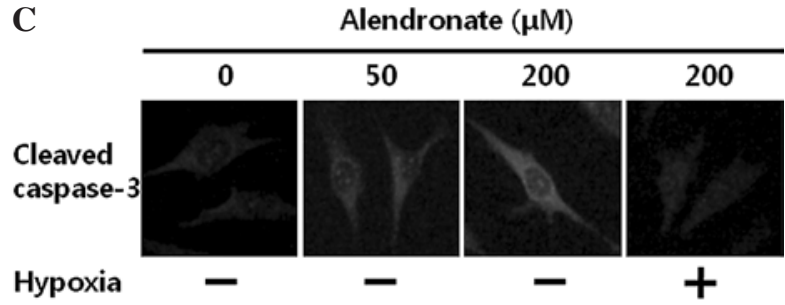

D

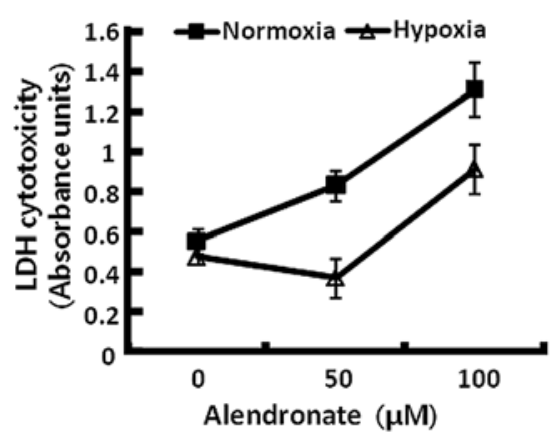

Figure 2. Apoptotic features of N-BP-induced cell death. (A) MG 63 cells were treated with $100 \mu \mathrm{M}$ alendronate (ALN) for $60 \mathrm{~h}$, with or without hypoxia for $72 \mathrm{~h}$, subjected to TUNEL assay and counterstained with propidium iodide. (B) MG 63 cells were treated with $100 \mu \mathrm{M}$ ALN for $24 \mathrm{~h}$, with or without hypoxia (HYPA) for $36 \mathrm{~h}$. Cell lysates were analyzed by immunoblotting using antibodies for cleaved caspase-3. (C) MG 63 cells were treated dose-dependently with ALN for $24 \mathrm{~h}$, with or without hypoxia for $36 \mathrm{~h}$. Cells were fixed by cold acetone and stained with cleaved caspase-3 and Alexa Fluor 546-conjugated secondary antibodies, followed by fluorescence microscope analysis. (D) Cytotoxicity was calculated by measuring the amount of LDH released from the cytosol of ALN-damaged cells into the supernatant. The results showed that the higher the amounts of ALN in the cell culture, the higher the cytotoxicity and hypoxia recovered ALN-induced cytotoxicity.

tion, which was evident in BP-treated cells when measured by the TUNEL assay, was inhibited by hypoxia (Fig. 2A). $\mathrm{BP}$ treatment resulted in caspase-3 activation, illustrated by an increase in its active form $(19 \mathrm{kDa})$, as assessed by Western blot analysis using an anti-cleaved caspase-3 antibody (Fig. 2B) and by immunofluorescent staining (Fig. 2C). BP-induced caspase-3 activation was decreased with hypoxia. Similar to the viability results, as the concentration of ALN increased, the apoptosis and cytotoxicity of the MG 63 cells was observed to increase. Exposure to hypoxic conditions decreased this effect (Fig. 2C and D). These data showed that hypoxia effectively inhibited MG 63 apoptosis and cytotoxicity caused by BPs. The hypoxic inhibition of BP-induced cytotoxicity was caused by blockade of the apoptotic pathway, including DNA fragmentation and the activation of caspase-3.

Exposure to hypoxia reduces the BP-induced increase in JNK phosphorylation in MG 63 cells. To determine the mechanisms underlying the hypoxic inhibition of BP-induced cell death, Rap 1A, a geranylgeranylation marker that binds to the nongeranylgeranylated form, was measured. As expected, ALN inhibited geranylgeranylation. This inhibition was reversed by $\mathrm{GGOH}$, which restores geranylgeranylation. However, hypoxia did not reverse the ALN-induced inhibition of geranylgeranylation. These results indicate that hypoxia does not regulate prenylation, but rather regulates cell survival through other signaling pathways.

To investigate the mechanisms of hypoxia regulation of BP-induced apoptosis, the JNK pathway was examined using
Western blotting and immunofluorescent staining. MG 63 cell exposure to ALN at a concentration of $100 \mu \mathrm{M}$ for $24 \mathrm{~h}$ caused JNK phosphorylation (Fig. 3B). Hypoxia inhibited the phosphorylation of JNK caused by ALN (Fig. 3B). Moreover, ALN-induced phosphorylation of JNK was inhibited by hypoxia in a time-dependent manner (Fig. 3C). These data revealed that exposure to hypoxic conditions decreased the up-regulation of JNK phosphorylation caused by BP treatment. Based on these data, it appears that JNK plays a pivotal role in BP-induced cell apoptosis, and that hypoxia has inhibitory effects on BP-induced cell apoptosis by the downregulation of JNK phosphorylation, but not by the regulation of prenylation.

Hypoxia induces BCL-xL activation. BCL-xL (BCL2-like 1 or BCL2L1) is a major anti-apoptotic protein of the Bcl-2 family that is overexpressed in many types of cancer, and is a key molecule underlying hypoxia-driven cell death resistance (4). Since Chen et al recently reported that BCL-xL is a target gene regulated by hypoxia-inducible factor- $1 \alpha$ (HIF-1 $\alpha$ ) (3) and BCL-xL is regulated by JNK (22-24), we investigated whether the anti-apoptotic effect of hypoxia is related to BCL-xL signaling.

Exposure of MG 63 cells to ALN at a concentration of $100 \mu \mathrm{M}$ for $24 \mathrm{~h}$ had a minimal effect on BCL-xL activation (Fig. 4A and B). However, hypoxia enhanced BCL-xL activation, as noted in the Western blots and immunofluorescent staining (Fig. 4A and B). These results indicate that hypoxia inhibits BP-induced MG 63 cell apoptosis by the BCL-xLinduced blockade of caspase-3 activation. 
A

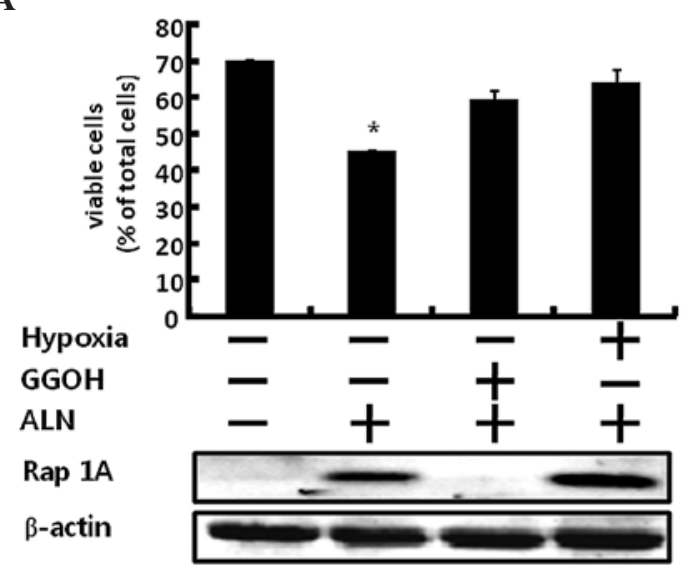

B

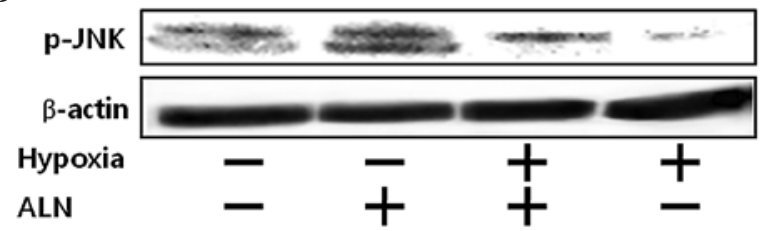

C

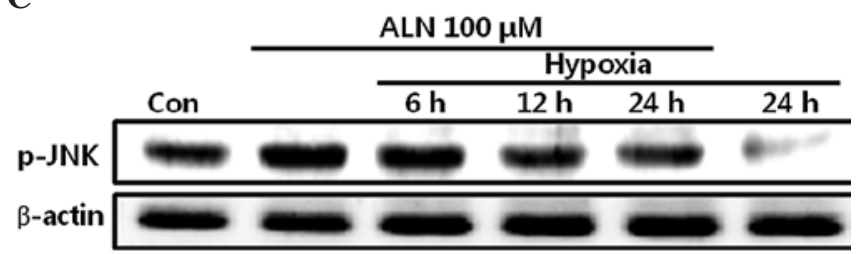

Figure 3. Hypoxia prevents the JNK phosphorylation by alendronate (ALN). (A) MG 63 cells were treated with $100 \mu \mathrm{M}$ ALN for $24 \mathrm{~h}$, with or without hypoxia for $36 \mathrm{~h}$, and lysates were collected and immunoblotted with antibodies specific for unprenylated Rap 1A and $\beta$-actin. (B) MG 63 cells were treated as described above, and cell lysates were analyzed by Western blotting using antibodies for p-JNK. (C) MG 63 cells were treated with $100 \mu \mathrm{M}$ ALN for $24 \mathrm{~h}$, with or without hypoxia in a time-dependent manner, and Western blotting was performed as described in A.

\section{Discussion}

Studies have shown that hypoxia enhances the expression of genes and proteins associated with survival. However, there have been no studies on whether hypoxia inhibits BP-induced MG 63 cell death.

This study revealed for the first time a protective effect of hypoxia on BP-related bone cell damage. The cell viability data, including crystal violet staining, trypan blue exclusion, MTT assays and microscopic observation, revealed that various BPs, including ALN, risedronate and zoledronate, induced bone cell death in a dose-dependent manner, and that hypoxic conditions inhibited the bone cell death effect of the BPs. Moreover, hypoxia was more effective at inhibiting cell death than exogenous GGOH. BPs are currently the major class of drugs used for the treatment of osteoporosis and other diseases characterized by increased bone resorption,
A

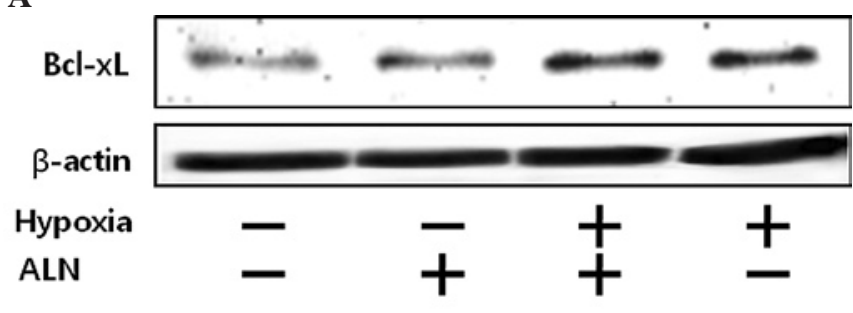

B

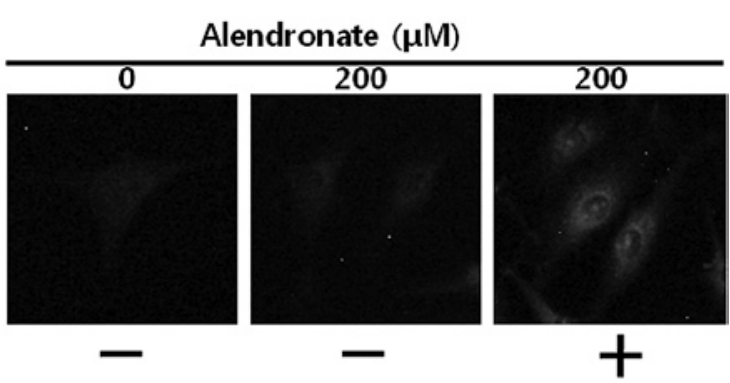

Hypoxia

Figure 4. Hypoxia prevents the activation of BCL-xL by alendronate (ALN). (A) MG 63 cells were treated with $100 \mu \mathrm{M}$ ALN for 24, with or without hypoxia for $36 \mathrm{~h}$, and cell lysates were analyzed by Western blotting using antibodies for BCL-xL. (B) MG 63 cells were treated as described in Fig. 2C, and cells were stained with BCL-xL antibodies and secondary antibodies conjugated with Alexa Fluor 488, followed by fluorescence microscope analysis.

such as Paget's disease, hypercalcemia and metastatic cancer in bone (36). Recently, there have been numerous reports of side effects associated with BP use, particularly ONJ (25). The exact mechanisms of ONJ are not known, but one of the suggested mechanisms is that BPs cause an excessive reduction in bone turnover, leading to the accumulation of microcracks that make the bone susceptible to necrosis when there is increased demand for osseous repair owing to trauma, such as tooth extraction $(28,29)$. Focusing on the mechanisms of an excessive reduction in bone turnover, our results suggest that hypoxic conditions have a protective effect on BP-related side effects such as ONJ.

The mechanism of BP-induced bone cell damage was also investigated. One of the rationales for using BPs in osteoporosis is that they inhibit bone resorption by inducing osteoclast apoptosis (38). Additionally, it has been reported that BPs actually suppress bone formation in vivo (39) and cause osteoblast apoptosis and inhibit bone nodule formation in vitro (40). Based on the current TUNEL assay results and the observed cleavage of caspase- 3 , we confirmed that the type of cell death caused by BPs was indeed apoptosis, and that this bone cell apoptosis was protected by pre-treatment under hypoxic conditions. These results confirm that hypoxia has a protective effect against bone cell apoptosis resulting from long-term BP treatment.

BPs exhibit apoptotic effects by inhibiting the prenylation of small G protein families (33). GGOH is an exogenous isoprenoid metabolite required for lipid modification (prenylation) of $\mathrm{G}$ protein families (37). By the addition of $\mathrm{GGOH}$, the prenylation of small $\mathrm{G}$ protein families occurs, blocking 
the apoptotic effects of BPs. The results of immunodetection for Rap 1A showed that the addition of GGOH reversed unprenylation by BPs. However, hypoxia did not reverse the ALN-induced inhibition of prenylation. These results demonstrated that hypoxia does not regulate prenylation inhibited by $\mathrm{BP}$, but rather regulates cell viability through other signaling pathways.

Various studies have shown that JNK acts as a key component of apoptosis regulation in several cell types (41). The JNK/SAPK signaling pathway is stimulated by a variety of stresses, and may be involved in diverse cellular activities including cell growth, differentiation and cell death. The persistent activation of the JNK/SAPK pathway often mediates the intracellular signaling that leads to cell death (42). Osteoblast and osteoclast exposure to ALN and pamidronate was found to result in the activation of caspase-3 and the activation of the p38 MAPK and JNK signaling pathways (40). Dunford et al recently reported that BPs cause apoptosis and activate the MAPK and JNK signaling pathways in osteoclasts and J774 macrophages in vitro (19). JNK induces cell apoptosis by phosphorylation and activation of the transcription factor p53 $(20,21)$. In the present study, when phosphorylation of JNK was detected in the MG 63 cells treated with ALN and with or without hypoxia in a time-dependant manner, the increase in JNK phosphorylation induced by BP treatment was gradually decreased by hypoxia. Based on these data, it appears that JNK has a pivotal role in BP-induced cell apoptosis, and that hypoxia confers inhibitory effects on BP-induced cell apoptosis by the down-regulation of JNK phosphorylation, but not by the regulation of prenylation.

Exposure of MG 63 cells to ALN had a minimal effect on BCL-xL activation, while hypoxia enhanced BCL-xL activation, as shown by immunodetection. BCL-xL (BCL2like 1 or BCL2L1) is a major anti-apoptotic protein of the Bcl-2 family overexpressed in many types of cancer, and is a key molecule underlying hypoxia-driven cell death resistance (4). Chen et al recently reported that BCL-xL is a target gene regulated by HIF-1 $\alpha$ (3). In addition, JNK has been shown to induce cell apoptosis by phosphorylation (and inactivation) of the anti-apoptotic proteins of the Bcl-2 family (22-24). Our results therefore demonstrated that HIF-1 $1 \alpha$, which is induced under hypoxic conditions, increased the expression of BCL-xL; thus, the hypoxic condition led to the blockage of apoptosis by inhibiting the cleavage of caspase-3. In addition, due to $\mathrm{BCL}-\mathrm{xL}$ regulation by JNK, the hypoxic condition-induced reduction of JNK phosphorylation led to the increase in BCL-xL proteins and cell survival. Since BCL-xL is regulated by HIF- $1 \alpha$ and JNK, further studies using HIF- $1 \alpha$ knockdown and JNK inhibitors are warranted. Through further study, gene therapy using HIF- $1 \alpha$ may be validated as a valuable treatment for the side effects arising from BP-induced cell damage.

In conclusion, the findings presented in this study clearly demonstrate that hypoxic conditions protect osteoblast-like cells from apoptosis induced by BPs via regulation of JNK phosphorylation and BCL-xL activation. These findings present the possibility that hypoxia or hypoxia-related genes, including HIF-1 $\alpha$, may be used as successful therapeutic tools for BP-related side effects such as osteonecrosis of the jaw.

\section{Acknowledgements}

This study was supported by the National Research Foundation of the Korea Grant funded by the Korean Government (200965822) and by the Regional Research Universities Program and the Center for Healthcare Technology Development.

\section{References}

1. Pouyssegur J, Dayan F and Mazure N: Hypoxia signalling in cancer and approaches to enforce tumour regression. Nature 441: 437-443, 2006

2. Boyle G and Travers S: Hypoxia: targeting the tumour. Anticancer Agents Med Chem 6: 281-286, 2006.

3. Chen N, Chen X, Huang R, et al: $\mathrm{Bcl}-\mathrm{xl}$ is a target gene regulated by hypoxia-inducible factor-1\{alpha\}. J Biol Chem 284: 10004-10012, 2009.

4. Dong $\mathrm{Z}$ and Wang J: Hypoxia selection of death-resistant cells. A role for Bcl-X(L). J Biol Chem 279: 9215-9221, 2004.

5. Graeber TG, Osmanian C, Jacks T, et al: Hypoxia-mediated selection of cells with diminished apoptotic potential in solid tumours. Nature 379: 88-91, 1996.

6. Harris AL: Hypoxia - a key regulatory factor in tumour growth. Nat Rev Cancer 2: 38-47, 2002.

7. Brizel D, Scully S, Harrelson J, et al: Tumor oxygenation predicts for the likelihood of distant metastases in human soft tissue sarcoma. Cancer Res 56: 941-943, 1996.

8. Cosse J, Ronvaux M, Ninane N, Raes M and Michiels C: Hypoxia-induced decrease in p53 protein level and increase in c-jun DNA binding activity results in cancer cell resistance to etoposide. Neoplasia 11: 976-986, 2009.

9. Geddes A, D'Souza S, Ebetino F and Ibbotson K: Bisphosphonates: structure-activity relationships and therapeutic implications. J Bone Miner Res 8: 265-306, 1994.

10. Roux C and Dougados M: Treatment of patients with Paget's disease of bone. Drugs 58: 823-830, 1999.

11. Kavanagh K, Guo K, Dunford J, et al: The molecular mechanism of nitrogen-containing bisphosphonates as antiosteoporosis drugs. Proc Natl Acad Sci USA 103: 7829-7834, 2006.

12. Van Beek E, Pieterman E, Cohen L, Lowik C and Papapoulos S: Farnesyl pyrophosphate synthase is the molecular target of nitrogen-containing bisphosphonates. Biochem Biophys Res Commun 264: 108-111, 1999.

13. Virtanen SS, Vaananen HK, Harkonen PL and Lakkakorpi PT: Alendronate inhibits invasion of PC-3 prostate cancer cells by affecting the mevalonate pathway. Cancer Res 62: 2708-2714, 2002.

14. Casey P: Biochemistry of protein prenylation. J Lipid Res 33: 1731-1731, 1992.

15. Van Beek E, Lowik C, van der Pluijm G and Papapoulos S: The role of geranylgeranylation in bone resorption and its suppression by bisphosphonates in fetal bone explants in vitro: a clue to the mechanism of action of nitrogen-containing bisphosphonates. J Bone Miner Res 14: 722-729, 1999.

16. Roelofs AJ, Thompson K, Gordon S and Rogers MJ: Molecular mechanisms of action of bisphosphonates: current status. Clin Cancer Res 12: S6222-S6230, 2006.

17. Fisher JE, Rogers MJ, Halasy JM, et al: Alendronate mechanism of action: geranylgeraniol, an intermediate in the mevalonate pathway, prevents inhibition of osteoclast formation, bone resorption, and kinase activation in vitro. Proc Natl Acad Sci USA 96: 133-138, 1999.

18. Coxon FP, Helfrich MH, Van't Hof R, et al: Protein geranylgeranylation is required for osteoclast formation, function, and survival: inhibition by bisphosphonates and GGTI-298. J Bone Miner Res 15: 1467-1476, 2000.

19. Dunford JE, Rogers MJ, Ebetino FH, Phipps RJ and Coxon FP: Inhibition of protein prenylation by bisphosphonates causes sustained activation of Rac, Cdc42, and Rho GTPases. J Bone Miner Res 21: 684-694, 2006.

20. Buschmann T, Potapova O, Bar-Shira A, et al: Jun NH2-terminal kinase phosphorylation of $\mathrm{p} 53$ on Thr- 81 is important for p53 stabilization and transcriptional activities in response to stress. Mol Cell Biol 21: 2743-2754, 2001. 
21. Cheng WH, Zheng X, Quimby FR, Roneker CA and Lei XG: Low levels of glutathione peroxidase 1 activity in selenium-deficient mouse liver affect c-jun N-terminal kinase activation and p53 phosphorylation on Ser-15 in pro-oxidant-induced aponecrosis. Biochem J 370: 927-934, 2003.

22. Mizukami Y, Yoshioka K, Morimoto S and Yoshida K: A novel mechanism of JNK1 activation. Nuclear translocation and activation of JNK1 during ischemia and reperfusion. J Biol Chem 272: 16657-16662, 1997.

23. Deng X, Xiao L, Lang W, Gao F, Ruvolo P and May WS Jr: Novel role for JNK as a stress-activated Bcl2 kinase. J Biol Chem 276 23681-23688, 2001.

24. Kharbanda S, Saxena S, Yoshida K, et al: Translocation of SAPK/JNK to mitochondria and interaction with Bcl-X(L) in response to DNA damage. J Biol Chem 275: 322-327, 2000.

25. Drake MT, Clarke BL and Khosla S: Bisphosphonates: mechanism of action and role in clinical practice. Mayo Clin Proc 83: 1032-1045, 2008.

26. Papapetrou PD: Bisphosphonate-associated adverse events. Hormones 8: 96-110, 2009.

27. Khosla S, Burr D, Cauley J, et al: Bisphosphonate-associated osteonecrosis of the jaw: report of a task force of the American Society for Bone and Mineral Research. J Bone Miner Res 22: $1479-1491,2007$.

28. Silverman SL and Landesberg R: Osteonecrosis of the jaw and the role of bisphosphonates: a critical review. Am J Med 122: S33-S45, 2009.

29. Marx R, Sawatari Y, Fortin M and Broumand V: Bisphosphonateinduced exposed bone (osteonecrosis/osteopetrosis) of the jaws risk factors, recognition, prevention, and treatment. J Oral Maxillofac Surg 63: 1567-1575, 2005.

30. Seol JW, Chaudhari AA, Lee YJ, et al: Regulation of DR-5 protein and mitochondrial transmembrane potential by gemcitabine, a possible mechanism of gemcitabine-enhanced trail-induced apoptosis. Oncol Rep 18: 523-529, 2007.

31. McAteer JA and Davis JM: Basic cell culture technique and the maintenance of cell lines. In: Basic Cell Culture: A Practical Approach. 2nd edition. Davis JM (ed). Oxford University Press, Oxford, pp93-148, 1994.

32. Perkins GL, Derfoul A, Ast A and Hall DJ: An inhibitor of the stretch-activated cation receptor exerts a potent effect on chondrocyte phenotype. Differentiation 73: 199-211, 2005.
33. Luckman SP, Hughes DE, Coxon FP, Graham R, Russell G and Rogers MJ: Nitrogen-containing bisphosphonates inhibit the mevalonate pathway and prevent post-translational prenylation of GTP-binding proteins, including ras. J Bone Miner Res 13: 581-589, 1998.

34. Inoue R, Matsuki NA, Jing G, Kanematsu T, Abe $\mathrm{K}$ and Hirata M: The inhibitory effect of alendronate, a nitrogencontaining bisphosphonate on the PI3K-Akt-NFkappaB pathway in osteosarcoma cells. Br J Pharmacol 146: 633-641, 2005.

35. Benford HL, Frith JC, Auriola S, Monkkonen J and Rogers MJ: Farnesol and geranylgeraniol prevent activation of caspases by aminobisphosphonates: biochemical evidence for two distinct pharmacological classes of bisphosphonate drugs. Mol Pharmacol 56: 131-140, 1999.

36. Shipman CM, Croucher PI, Russell RG, Helfrich MH and Rogers MJ: The bisphosphonate incadronate (YM175) causes apoptosis of human myeloma cells in vitro by inhibiting the mevalonate pathway. Cancer Res 58: 5294-5297, 1998.

37. Russell RG, Watts NB, Ebetino FH and Rogers MJ: Mechanisms of action of bisphosphonates: similarities and differences and their potential influence on clinical efficacy. Osteoporos Int 19: 733-759, 2008.

38. Rodan GA and Fleisch HA: Bisphosphonates: mechanisms of action. J Clin Invest 97: 2692-2696, 1996.

39. Tobias JH, Chow JW and Chambers TJ: 3-Amino-1-hydroxypropylidine-1-bisphosphonate (AHPrBP) suppresses not only the induction of new, but also the persistence of existing boneforming surfaces in rat cancellous bone. Bone 14: 619-623, 1993.

40. Idris AI, Rojas J, Greig IR, Van't Hof RJ and Ralston SH: Aminobisphosphonates cause osteoblast apoptosis and inhibit bone nodule formation in vitro. Calcif Tissue Int 82: 191-201, 2008.

41. Lu PZ, Lai CY and Chan WH: Caffeine induces cell death via activation of apoptotic signal and inactivation of survival signal in human osteoblasts. Int J Mol Sci 9: 698-718, 2008.

42. Davis RJ: Signal transduction by the JNK group of MAP kinases. Cell 103: 239-252, 2000. 